\section{RMD Open}

Rheumatic \&

Musculoskeletal Diseases
To cite: Kernder A, Morf H, Klemm P, et al. Digital rheumatology in the era of COVID-19: results of a national patient and physician survey. RMD Open 2021;7:e001548. doi:10.1136/ rmdopen-2020-001548

- Additional material is published online only. To view, please visit the journal online (http://dx.doi.org/10.1136/ rmdopen-2020-001548).

Received 14 December 2020 Revised 12 February 2021 Accepted 15 February 2021

Check for updates

(C) Author(s) (or their employer(s)) 2021. Re-use permitted under CC BY-NC. No commercial re-use. See rights and permissions. Published by BMJ.

For numbered affiliations see end of article.

Correspondence to Dr Martin Krusche; martin.krusche@charite.de

\title{
Digital rheumatology in the era of COVID-19: results of a national patient and physician survey
}

Anna Kernder, ${ }^{1,2}$ Harriet Morf, ${ }^{2,3}$ Philipp Klemm, ${ }^{2,4}$ Diana Vossen, ${ }^{2,5}$ Isabell Haase,, ${ }^{1,2}$ Johanna Mucke, ${ }^{1,2}$ Marco Meyer, ${ }^{2,6}$ Arnd Kleyer, ${ }^{2,3}$ Philipp Sewerin (10) , ${ }^{1,2}$ Gerlinde Bendzuck, ${ }^{7}$ Sabine Eis, ${ }^{7}$ Johannes Knitza (i) , ${ }^{2,3}$ Martin Krusche (10) 2,8

\section{ABSTRACT}

Objective To analyse the impact of the COVID-19 pandemic on rheumatic patients' and rheumatologists' usage, preferences and perception of digital health applications (DHAs).

Methods A web-based national survey was developed by the Working Group Young Rheumatology of the German Society for Rheumatology and the German League against Rheumatism. The prospective survey was distributed via social media (Twitter, Instagram and Facebook), QR code and email. Descriptive statistics were calculated, and regression analyses were performed to show correlations. Results We analysed the responses of 299 patients and 129 rheumatologists. Most patients $(74 \%)$ and rheumatologists $(76 \%)$ believed that DHAs are useful in the management of rheumatic and musculoskeletal diseases (RMDs) and felt confident in their own usage thereof (90\%; $86 \%$ ). $38 \%$ of patients and $71 \%$ of rheumatologists reported that their attitude had changed positively towards DHAs and that their usage had increased due to COVID-19 $(29 \% ; 48 \%)$. The majority in both groups agreed on implementing virtual visits for follow-up appointments in stable disease conditions. The most reported advantages of DHAs were usage independent of time and place (76.6\%; $77.5 \%$ ). The main barriers were a lack of information on suitable, available DHAs (58.5\%; $41.9 \%)$, poor usability (42.1\% of patients) and a lack of evidence supporting the effectiveness of DHAs (23.2\% of rheumatologists). Only a minority $(<10 \%$ in both groups) believed that digitalisation has a negative impact on the patient-doctor relationship.

Conclusion The COVID-19 pandemic instigated an increase in patients' and rheumatologists' acceptance and usage of DHAs, possibly introducing a permanent paradigm shift in the management of RMDs.

\section{INTRODUCTION}

Rheumatic and musculoskeletal diseases (RMDs) are complex chronic conditions that require regular monitoring and treatment. Once an RMD has been diagnosed, regular disease follow-up is necessary. This includes the assessment of treatment response, symptom tracking, blood exams, monitoring

\section{Key messages}

What is already known about this subject?

- During the COVID-19 pandemic, many consultations had to be cancelled or were switched to a virtual format.

- This study analyses the use and perception of digital health applications (DHAs) by rheumatic and musculoskeletal disease (RMD) patients and rheumatologists in Germany.

What does this study add?

- Patients and rheumatologists consider DHAs to be useful in the management of rheumatic diseases.

- The attitude towards DHAs has improved, and implementation has increased due to COVID-19.

- Patients and rheumatologists prefer synchronous monitoring, as opposed to flexible asynchronous monitoring.

- A lack of information about suitable DHAs was the greatest barrier for DHA usage among RMD patients and rheumatologists.

How might this impact on clinical practice?

- In stable disease conditions, virtual visits can be implemented for follow-up appointments.

- The increased availability of information on DHAs, as well as our growing experience with their implementation, will likely cause a steady and lasting increase in DHA usage in rheumatology.

for adverse events and re-evaluation of treatment indications.

The COVID-19 pandemic presents an unprecedented challenge to public health in general, and, in particular, in the care of the chronically ill patients. At the beginning of the COVID-19 pandemic, severe changes and cuts in rheumatological care were made. ${ }^{12}$ Due to pandemic containment measurements, many patient appointments had to be cancelled ${ }^{3}$ or were converted to telephone or video consultations. $^{245}$ 
Many practitioners believe that telemedicine holds great potential for the management of RMDs. ${ }^{6}$ Digitalisation now affects $90 \%$ of the healthcare system and has already led to many changes for both patients and doctors, crucially impacting the patient-doctor relationship. ${ }^{7}$ It has already been shown that rheumatology patients are willing to use mobile health technologies to improve their disease status and to track symptoms and disease activity. ${ }^{8}$ Also, the use of digital health applications (DHAs) by rheumatologists has increased over the past years. ${ }^{10}$ Even though studies demonstrating positive effects of applications ('apps') in the field of rheumatology are still lacking, ${ }^{11}$ the process of DHA implementation in routine healthcare is expected to be further accelerated by the introduction of the Digital Health Care Act, which grants all those with statutory health insurance in Germany the reimbursement for certain DHAs. $^{12}$

For the successful development and implementation of telemedical concepts for the management of RMDs, both the patient's and the rheumatologist's perspective are crucial. ${ }^{13-15}$ The main question is if and how adequate treatment can take place digitally in the future. This survey addressed this question by examining the usage and perception of digital health applications (such as video consultations, medical apps, digital appointments, diaries, questionnaires, online courses or the use of symptom checkers) by RMD patients and rheumatologists in Germany. In particular, changes in regard to these aspects during the COVID-19 pandemic were recorded.

\section{METHODS}

The web-based survey was created by members of the Working Group Young Rheumatology (Arbeitsgemeinschaft Junge Rheumatologie) and the German League against Rheumatism (Deutsche Rheuma-Liga Bundesverband e.V.). An online expert panel identified three areas of interest to investigate: (1) usage of DHAs, (2) DHA preferences and (3) DHA barriers and advantages.

In order to investigate the identified areas of interest, an expert panel designed a questionnaire in analogy to the EULAR recommendation task force standard operating procedures ${ }^{16}$ in two separate online meetings after individual literature research.

After both meetings, the questionnaire was shared with members of the German League against Rheumatism who commented on and edited the draft version and approved the final questionnaire (online supplemental material 1).

The web-based survey (SurveyMonkey Inc) was accessible from 9 September 2020 to 15 October 2020 and distributed via social media (Twitter, Instagram and Facebook) (online supplemental material 2), a QR code and/or email. All patients with self-reported RMDs and rheumatologists (specialists and trainees) were eligible. All participants gave consent. There were no exclusion criteria.
Table 1 Patients characteristics (mean \pm SEM or $\mathrm{n}(\%)$ )

Patients $\mathrm{n}=\mathbf{2 9 9}$

(100\%)

\begin{tabular}{ll}
\hline Age, years & $48.7 \pm 14.1$ \\
Women & $239(79.9)$ \\
\hline $\begin{array}{ll}\text { Diagnosis } \\
\text { Rheumatoid arthritis }\end{array}$ & $134(44.8)$ \\
\hline Psoriasis arthritis & $36(12.0)$ \\
\hline Spondylarthritis & $41(13.7)$ \\
\hline Gout & $6(2.0)$ \\
\hline Systemic sclerosis & $30(10.0)$ \\
\hline Others & $52(17.4)$ \\
\hline Travel time to rheumatologist, $\min$ & $45.8 \pm 35.2$ \\
\hline
\end{tabular}

Reporting the study's methodology and results was done according to the Checklist for Reporting Results of Internet E-Surveys. ${ }^{17}$ Descriptive and summary statistics were used. The analyses were performed using IBM SPSS Statistics V.20 Windows (SPSS Inc, Chicago, Illinois, USA) and Excel Windows (Microsoft GmbH, Unterschleißheim). Absolute and relative frequencies were calculated and depicted in tabular and graphical form. Regression analyses were performed to show correlations.

\section{RESULTS}

Two hundred and ninety-nine patients and 129 rheumatologists completed the online survey. The mean age of participating patients was 49 years (15-82 years), and the majority was female $(\mathrm{n}=239,79.9 \%)$. Various RMDs were reported by participating patients, with rheumatoid arthritis (RA) being the most common disease $(n=134,44.8 \%)$. A percentage of $74.6(n=223)$ of patients reported to use apps several times a day on a smartphone, $14 \%(n=42)$ used apps once daily and $3.7 \%(n=11)$ once weekly. Only $4 \%(n=12)$ of the patients stated to never use apps.

The physicians' genders were balanced $(48.5 \% \quad(n=63)$ female). A percentage of 74.1 of rheumatologists were clinicians $(46.1 \%(n=59)$ in a university hospital, $28.1 \%$ $(\mathrm{n}=36)$ in a non-university hospital) and $25.8 \%(\mathrm{n}=33)$ worked in a private practice. Participant details are given in tables 1 and 2.

\section{Usage of digital health applications}

Ninety per cent $(n=269)$ of patients stated that they were able to use DHAs (table 3) and $74.2 \%(\mathrm{n}=222)$ described the usage as useful for managing their disease, whereas $2.7 \%(n=8)$ disagreed. The higher the age of patients, the lower the overall app usage (beta $=0.312 ; \mathrm{R}^{2}=0.097$; $\mathrm{p}=0.001)$ and the lower their confidence in using apps (beta=-0.195; $\mathrm{R}^{2}=0.038 ; \mathrm{p}=0.001$ ), adjusted for gender and travel time to their rheumatologist.

Seventy-six per cent $(\mathrm{n}=98)$ of rheumatologists described the use of DHAs for managing the patient's 
Table 2 Physicians charactersitics (n (\%))

Rheumatologists

$n=129(100 \%)$

\begin{tabular}{|c|c|}
\hline Women & $63(48.8)$ \\
\hline \multicolumn{2}{|l|}{ Age (years) } \\
\hline $21-30$ & $17(13.2)$ \\
\hline $31-40$ & $44(34.1)$ \\
\hline $41-50$ & $28(21.7)$ \\
\hline $51-60$ & $30(23.3)$ \\
\hline$>60$ & $10(7.8)$ \\
\hline Resident & $40(31.0)$ \\
\hline Consultant & $89(69.0)$ \\
\hline \multicolumn{2}{|l|}{ Working place } \\
\hline University hospital & $59(46.1)$ \\
\hline Non-university hospital & $36(28.1)$ \\
\hline Private practice & $33(25.8)$ \\
\hline
\end{tabular}

Table 3 Usage of digital health applications before and after COVID-19 pandemic, $\mathrm{n}(\%)$

$\begin{array}{lll}\text { Characteristics } & \begin{array}{l}\text { Patients } \\ \mathrm{n}=\mathbf{2 9 9}(100 \%)\end{array} & \text { Rheumatologists } \\ \mathrm{n}=129(100 \%)\end{array}$

\begin{tabular}{|c|c|c|}
\hline \multicolumn{3}{|c|}{$\begin{array}{l}\text { I believe using digital health applications (eg, medical apps, } \\
\text { video consultation and online pharmacies) is useful for } \\
\text { managing my disease, } n(\%)\end{array}$} \\
\hline Strongly disagree & $8(2.7)$ & $0(0.0)$ \\
\hline Disagree & $11(3.7)$ & $2(1.6)$ \\
\hline Neutral & $58(19.4)$ & 29 (22.5) \\
\hline Agree & $138(46.2)$ & $62(48.1)$ \\
\hline Strongly agree & $84(28.1)$ & $36(27.9)$ \\
\hline \multicolumn{3}{|c|}{$\begin{array}{l}\text { Has your attitude towards digital health Apps changed due } \\
\text { to the COVID-19 pandemic?, } \mathrm{n}(\%)\end{array}$} \\
\hline It changed positively & $112(37.5)$ & $92(71.3)$ \\
\hline It changed negatively & $2(0.7)$ & $3(2.3)$ \\
\hline $\begin{array}{l}\text { It has been } \\
\text { unaffected }\end{array}$ & 185 (61.9) & $34(26.4)$ \\
\hline \multicolumn{3}{|c|}{$\begin{array}{l}\text { Do you use digital health apps more regularly since the } \\
\text { COVID-19 pandemic?, } \mathrm{n}(\%)\end{array}$} \\
\hline Yes & $88(29.4)$ & $62(48.1)$ \\
\hline No & $211(70.6)$ & $67(51.9)$ \\
\hline \multicolumn{3}{|c|}{$\begin{array}{l}\text { I feel able to use digital } \\
\text { health apps, } n(\%)\end{array}$} \\
\hline Strongly disagree & $6(2.0)$ & $1(0.8)$ \\
\hline Disagree & $3(1.0)$ & $3(2.3)$ \\
\hline Neutral & $21(7.0)$ & $15(11.6)$ \\
\hline Agree & $127(42.5)$ & $61(47.3)$ \\
\hline Strongly agree & $142(47.5)$ & $49(38.0)$ \\
\hline
\end{tabular}

Patients and rheumatologists were asked to indicate if they believe in the usage of DHA for managing the disease and if their attitude has changed during the COVID-19 pandemic.

DHA, digital health application. disease as useful; only $1.6 \%(\mathrm{n}=2)$ disagreed. A percentage of $85.5(n=110)$ of physicians stated that they are able to use DHAs (table 3). No significant difference in gender, age, degree of training and workplace was noted.

Due to the COVID-19 pandemic, the attitude towards DHAs changed positively in $37.5 \%$ of patients $(n=112)$ and $71.3 \%$ of rheumatologists $(\mathrm{n}=92)$. Twenty-nine per cent of patients $(\mathrm{n}=88)$ and $48.1 \%$ of rheumatologists $(n=62)$ reported using DHAs more regularly (table 3$)$.

\section{DHA preferences}

At the time of the survey, informative DHAs $(63.2 \%$, $\mathrm{n}=189)$ and symptom checkers $(40.5 \%, \mathrm{n}=121)$ were most often used by patients. Digital disease-related questionnaires, diary DHAs and therapy DHAs, as well as video consultations, were planned to be used more often/ frequently in the future. Self-collected blood samples at home with digital access to results showed different levels of acceptance: $51.2 \%$ of patients $(n=153)$ reported no interest and $43.5 \%(n=128)$ could imagine the usage of this technique in the future (details are given in figure 1).

Most frequently, patients stated that video consultations are possible for follow-up $(40.6 \%, \mathrm{n}=71)$ and emergency appointments $(38.3 \%, \mathrm{n}=67)$. A percentage of 58.9 $(\mathrm{n}=176)$ of the patients affirmed that time-synchronous digital consultation could complement physical appointments (figure 2).

In addition, $81.3 \%(\mathrm{n}=243)$ of patients and $85.3 \%$ $(n=110)$ of rheumatologists reported to be willing to skip an on-site appointment if the patient's disease is stable and he or she could indicate his or her well-being by using a DHA (figure 3).

\section{Barriers and advantages of DHAs}

The effect of digitalisation on the patient-physician relationship was described variably, with $26.8 \%(\mathrm{n}=80)$ of patients evaluating it positively and $10.7 \% \quad(n=32)$ negatively, while $10.4 \%(\mathrm{n}=31)$ stated no influence. The majority described both positive and negative aspects of digitisation on the patient-doctor relationship (42.1\%, $\mathrm{n}=126$ ). A comparable trend was seen among rheumatologists. A percentage of $48.1(n=68)$ described positive and negative aspects of digitisation. A percentage of 32.6 $(n=42)$ stated a positive and only $8.5 \%(n=11)$ a negative attitude. Details are given in figure 4.

Too little information concerning suitable DHAs was the most mentioned barrier in using DHAs, affirmed by 175 patients $(58.5 \%)$ and 54 rheumatologists $(41.9 \%)$. Second, patients stated the lack of usability $(42.1 \%$, $\mathrm{n}=126$ ), whereas rheumatologists remarked too little evidence for the benefits of DHAs $(23.3 \%, n=30)$. Other barriers were poor quality, concerns about data protection, high costs and the lack of suitable equipment (such as a poor internet connection or old devices). Only 7 rheumatologists $(5.4 \%)$ and 27 patients $(9 \%)$ stated no need because of satisfaction with current analogous solutions. 

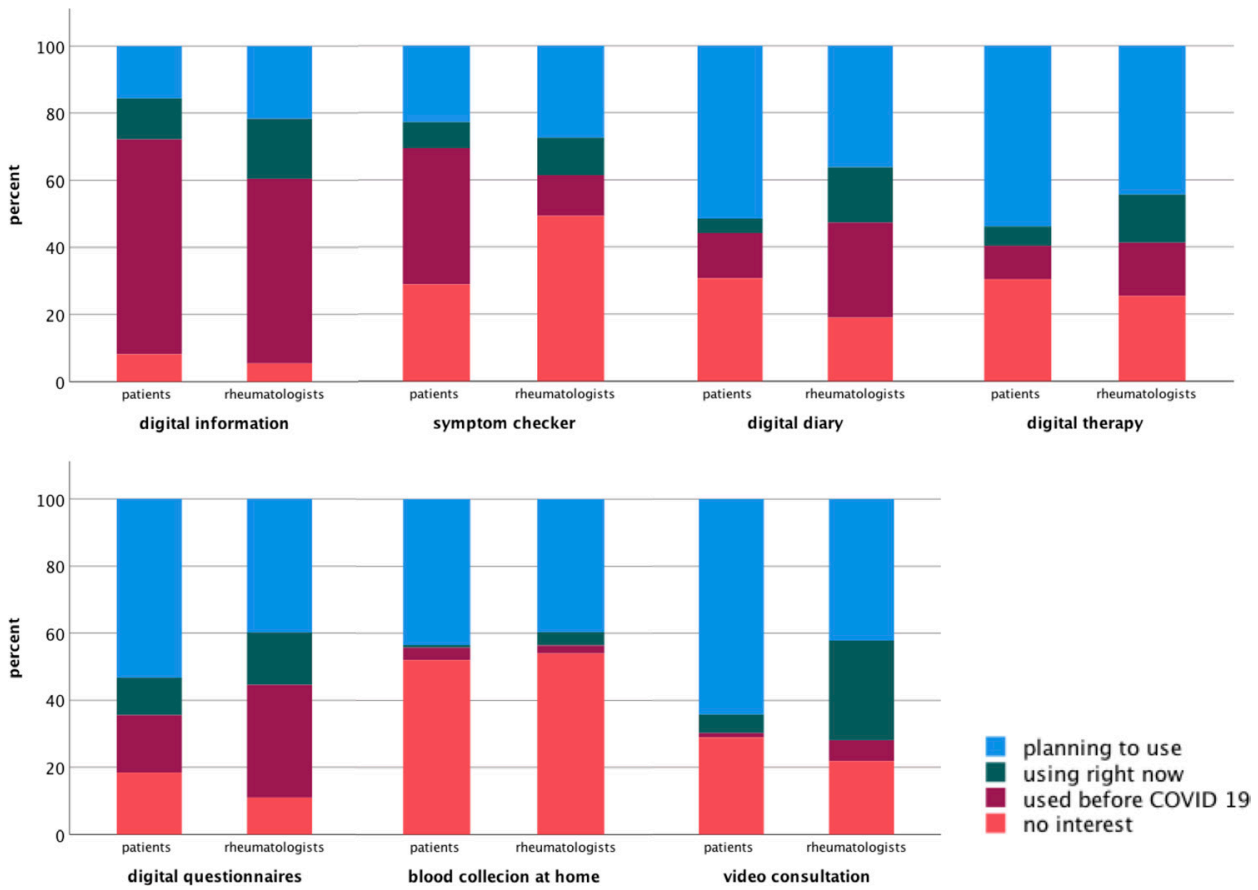

Figure 1 Usage or recommendation of digital health applications. Patients and rheumatologists were asked to indicate the specific digital health applications (DHAs) they used or were recommended. Potential DHAs include digital information, symptom checkers, digital diaries, therapy and questionnaires, blood collection at home and video consultations. The percentage of patients and rheumatologists who indicated one of four levels of usage (planned, currently used, already used prior to COVID-19 or no interest) is shown.

The most mentioned advantage of DHAs by both physicians and patients was the ability to use them independently of location and time of day and the subsequent flexibility. Additional advantages include detailed documentation, cost-saving, more opportunities to provide information, diagnostics and therapy, as well as better preparation for the patient-doctor discussion. Only 18 patients $(6 \%)$ and 1 rheumatologist $(0.8 \%)$ did not see any advantages of DHAs (details are indicated in table 4).

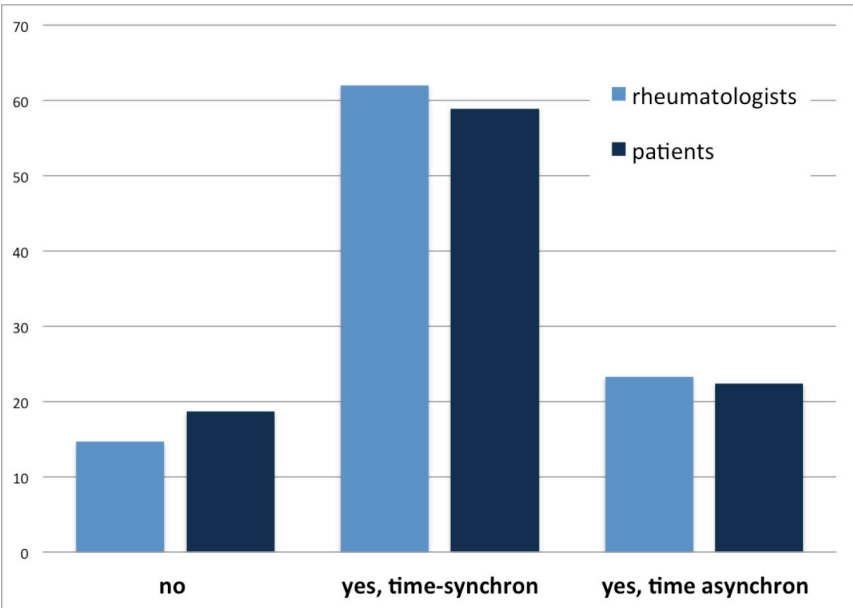

Figure 2 Potential usage of video consultations in per cent. Rheumatologists and patients were asked about perceivable purposes of video consultations.

\section{DISCUSSION}

We reported findings from a conjoint survey assessing both patients' and physicians' perspectives on digitalisation in rheumatology during the COVID-19 pandemic. The survey explored themes relating to: (1) the usage of digital health applications (DHAs), (2) preferences for specific DHAs and (3) the perceived advantages

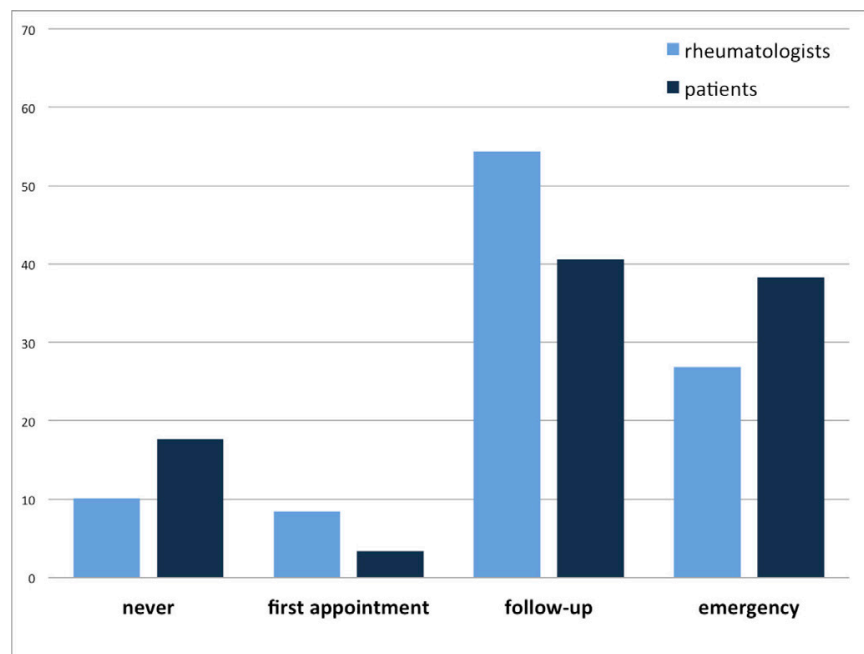

Figure 3 Percentage of rheumatologists and patients who are/are not willing to skip a real-life appointment and substitute it with a digital health application (DHA) in stable disease. Agreeing rheumatologists and patients were asked if they prefer time-synchronous or time-asynchronous DHAs. 


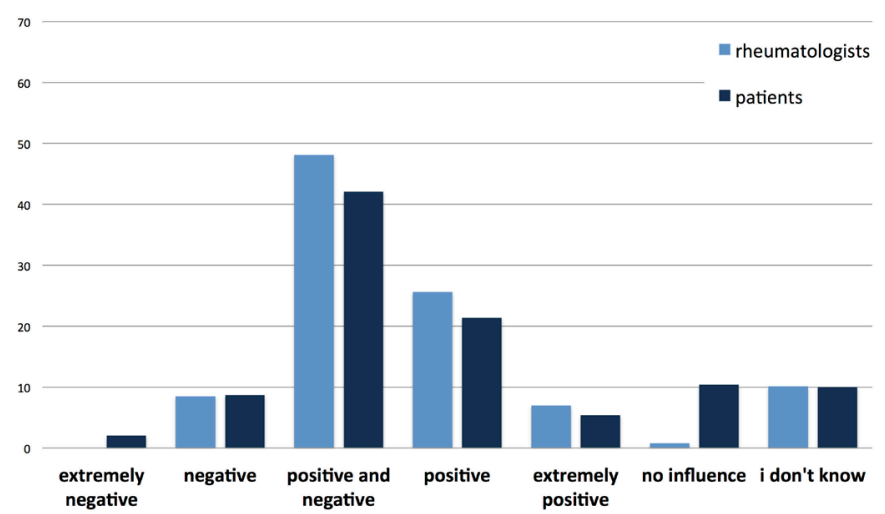

Figure 4 Rheumatologists' and patients' attitudes towards digitisation and its effect on the patient-doctor relationship in per cent. Most frequently, both positive and negative aspects of digitisation were reported by rheumatologists and patients.

and barriers of DHAs. In this survey study, numerous patients and rheumatologists reported a positive attitude and increased usage of DHAs due to the COVID-19 pandemic in Germany.

In line with previous patient surveys, ${ }^{9}$ the majority of patients stated that they regularly used mobile apps on their smartphone, believed that they were able to use DHAs and that using DHAs was beneficial for managing their RMD.

Interestingly, in contrast to rheumatologists, the majority of patients indicated that they used symptom checkers. This technology enables a low-barrier digital health check to assess disease symptoms. Frequent use could reflect patients' increased need for security. However, there is still little evidence to support the positive benefits of symptom checker usage. This might explain the reported reluctance of rheumatologists in recommending symptom checkers to their patients. ${ }^{16}$

Both groups showed an increased interest in the implementation of digital therapies to complement conventional therapies, that is, educational online courses. However, noteworthily, these resources were, at the time of the survey, rarely used, indicating the need for better quality material and the effective promotion of existing programmes. To reduce infection risk during consultations and to save time and clinic resources, selfadministered blood tests in combination with digital monitoring might complement clinical practice in the future. ${ }^{18} 19$ Gossec et $a l^{20}$ were able to demonstrate that wearable data was able to predict disease flares in RA and axial spondyloarthritis ( $\mathrm{SpA})$ patients. Furthermore, the feasibility of CRP quick tests for a rapid on-site disease activity assessment was shown in SpA patients. ${ }^{19}$ However, patients were somewhat reluctant to use applications such as self-administered blood tests or wearables for disease monitoring in the future. This may be because many of these solutions are concepts that currently remain foreign to the patient and/or raise concerns about digital overload and potential data violation.

Due to COVID-19 containment measures, many physical appointments had to be postponed or were changed to telehealth consultations. In line with the literature, the majority of rheumatologists and patients reported that follow-up appointments were most suited to videoconsultations, as were emergency appointments. ${ }^{121}$ Noteworthily, most patients were interested in the concept of video consultations; however, only a minority had previously engaged in one $(6.7 \%)$. Consequently, of all listed DHAs, rheumatologists reported the greatest COVID-19 induced uptake for video consultations. A majority in both groups indicated that they would be willing to skip an on-site appointment if the patients were able to indicate their well-being via a DHA. Interestingly, the analysis showed that synchronous monitoring via telephone or video consultation was, in both groups, preferred to flexible asynchronous monitoring, for example, via digital questionnaires. These findings are supported by a preCOVID-19 study by Ferucci $e t a l .^{22}$ The authors reported few differences between outcome and quality of care for patients with RA treated with telemedicine compared with physical follow-up treatment, concluding that it is reasonable to incorporate telehealth into routine care for patients with RA.

Table 4 Advantages and barriers of DHA, $n(\%)$

\begin{tabular}{lcclcc}
\hline Advantages & Patients & Rheumatologists & Barriers & Patients & Rheumatologists \\
\hline Location independence & $229(76.6)$ & $100(77.5)$ & Too little information & $175(58.5)$ & $54(41.9)$ \\
Time independence & $223(74.6)$ & $94(72.9)$ & Too little evidence of benefits & $36(12.0)$ & $30(23.3)$ \\
Detailed documentation & $97(32.4)$ & $47(36.4)$ & Poor quality of current apps & $47(15.7)$ & $29(22.5)$ \\
Cost saving & $95(31.8)$ & $37(28.7)$ & Concerns about data protection & $52(17.4)$ & $25(19.4)$ \\
More information & $88(29.4)$ & $38(29.5)$ & Lack of usability & $126(42.1)$ & $17(13.2)$ \\
Independence of doctors & $36(12.0)$ & - & Lack of accessibility & $4(1.3)$ & - \\
More flexibility & $107(36.8)$ & $77(59.7)$ & High costs & $4(1.3)$ & $23(17.8)$ \\
Preparation for discussion* & $46(15.4)$ & - & No suitable equipment & $17(5.7)$ & $11(8.5)$ \\
No advantages at all & $18(6.0)$ & $1(0.8)$ & Lack of user competence & $9(3.0)$ & - \\
& & & No Need & $39(13.0)$ & $12(9.3)$ \\
\hline
\end{tabular}

*Patients and rheumatologists were asked about the advantages and barriers of DHAs. Multiple answers were allowed. Patients had two additional potential advantages and potential barriers to choose from. 
An important aspect for the use and acceptance of digitalisation in medicine is the impact these technologies have on the patient-doctor relationship. ${ }^{23}$ In principle, our survey showed a positive trend in the perception of digitisation and its influence. Only the minority $(0.7 \%$ of patients and $8.5 \%$ of physicians) saw potential negative effects. However, the majority in both groups currently stated a mixed perception of this topic. Unfortunately, the different aspects of this topic were not further specified in the survey. However, the loss of physical contact for examinations and difficulties in establishing an emotional relationship is regarded as a disadvantage by some authors ('emotional and physical gap'). ${ }^{24}$ Furthermore, some patients, especially the elderly or those with a poor socioeconomic background, may not have the equipment and skills to use telehealth solutions, causing a digital divide based on age and income. ${ }^{1}$

However, the use of digital tools offers both sides a variety of new opportunities, such as new ways of communication and knowledge exchange (ie, via social media), ${ }^{25}$ new possibilities for identifying diagnoses, ${ }^{26}{ }^{27}$ personalised treatment and disease monitoring via digital tools (such as apps or wearables), ${ }^{28}$ as well as an efficient and simple exchange of electronic information for both clinical and scientific purposes. ${ }^{629}$

Almost all patients and rheumatologists identified advantages in using DHAs: implementation independent of time and place and general flexibility were stated most often. Interestingly, in contrast to 46 patients (15.4\%), no rheumatologist thought that DHAs might help in the preparation of a face-to-face appointment. Similar to previous surveys, the main barrier was a lack of information concerning suitable DHAs. ${ }^{13}$ For patients, the second greatest barrier was poor DHA usability, while for rheumatologists, it was too little evidence supporting DHA usage. This highlights the need for DHA studies, as expressed previously. ${ }^{1230}$ To ensure high usability, it is advisable to integrate patients in the early phases of DHA development. ${ }^{11}$ Unsatisfactory DHA skills were rarely stated as a barrier, similarly to costs.

The online format of our survey enabled broad accessibility to a potentially diverse sample of RMD patients and physicians. Due to the completely anonymous nature of the survey, the response rate could not be measured. The online nature of our survey, however, also potentially introduces a selection bias for digitally inclined users. The data collection transpired entirely digitally; therefore, patients and doctors with lower technical or digital competencies may have been missed. Lack of internet access or the availability to a modern smartphone was also identified as an issue regarding the German COVID-19 tracing app. ${ }^{3132}$ The interpretation of the digital survey results should therefore be carried out cautiously, as we cannot entirely exclude the possibility that not all RMD patients (especially the elderly) were able to participate in the survey. The survey was conducted between 9 September and 15 October. During this time, Germany was in the phase between the first and the second
European COVID-19 waves. The results should therefore be carefully interpreted in the context of this timeframe. It can be assumed that the acceptance will continue to change, as the use of telemedicine services is likely to further increase in the future due to ongoing pandemic containment measures.

To our knowledge, this is the first conjoint analysis assessing both patient and physician perspectives on digitalisation in rheumatology during the COVID-19 pandemic. Patient representatives were involved at all stages. We believe that our results may guide future recommendations, research and, most importantly, clinical practice. Our results highlight the current need for clinical studies and, in preparation for these studies, the implementation of guidelines for the use of telemedicine in rheumatology. ${ }^{11}$

\section{Author affiliations}

${ }^{1}$ Department of Rheumatology \& Hiller Research Unit, Heinrich Heine University Düsseldorf, Düsseldorf, Germany

${ }^{2}$ Working Group Young Rheumatology, German Society for Rheumatology, Berlin, Germany

${ }^{3}$ Department of Internal Medicine 3 - Rheumatology and Immunology, Erlangen University Hospital, Erlangen, Germany

${ }^{4}$ Department of Rheumatology, Immunology, Osteology, Kerckhoff-Klinik GmbH, Bad Nauheim, Germany

${ }^{5}$ Department of Rheumatology, St. Elisabeth Hospital, Meerbusch, Germany ${ }^{6}$ Department of Rheumatology, Bad Bramdsted Hospital, Bad Bramstedt, Germany

${ }^{7}$ Deutsche Rheuma-Liga Bundesverband e.V, Bonn, Germany

${ }^{8}$ Deaprtment of Rheumatology and Clinical immunology, Charite Medical Faculty Berlin, Berlin, Germany

Twitter Johannes Knitza @JK77775 and Martin Krusche @kruschemartin

Acknowledgements The authors would like to thank the following persons and societies for their great effort, distributing the online survey: $\mathrm{P}$ Aries, A Hueber, $\mathrm{E}$ Feist, C Fiehn, P Korsten, I Kötter, F Mühlensiepen, A Pfeil, M Rudwaleit, M Welcker, S Zinke, Deutsche Vereinigung Morbus Bechterew e.V., Deutsche Rheuma-Liga Bundesverband e. V. and Sklerodermie Selbsthilfe e.V.

Contributors All authors designed the study and contributed to data collection. AK and HM performed the data analyses. JK and MK drafted the first version of the manuscript. All coauthors were involved in the critical interpretation of the results, discussed the findings together, critically reviewed the manuscript and approved its final version. AK and HM share the first authorship, and JK and MK share the last authorship.

Funding The authors have not declared a specific grant for this research from any funding agency in the public, commercial or not-for-profit sectors.

Competing interests None declared.

\section{Patient consent for publication Not required.}

Ethics approval The study was approved by the ethics committee of the medical faculty of the University of Erlangen-Nuremberg, Germany (348_20 B).

Provenance and peer review Not commissioned; externally peer reviewed.

Data availability statement All data relevant to the study are included in the article or uploaded as supplementary information. Data are available on reasonable request. The data will be shared if there is a reasonable request for it.

Open access This is an open access article distributed in accordance with the Creative Commons Attribution Non Commercial (CC BY-NC 4.0) license, which permits others to distribute, remix, adapt, build upon this work non-commercially, and license their derivative works on different terms, provided the original work is properly cited, appropriate credit is given, any changes made indicated, and the use is non-commercial. See: http://creativecommons.org/licenses/by-nc/4.0/.

\section{ORCID iDs}

Philipp Sewerin http://orcid.org/0000-0001-8465-6207

Johannes Knitza http://orcid.org/0000-0001-9695-0657

Martin Krusche http://orcid.org/0000-0002-0582-7790 


\section{REFERENCES}

1 Mehta B, Jannat-Khah D, Fontana MA, et al. Impact of COVID-19 on vulnerable patients with rheumatic disease: results of a worldwide survey. RMD Open 2020;6:e001378.

2 Freudenberg S, Vossen D. Auswirkungen von COVID-19 auf die rheumatologische Versorgung : Eine nationale Umfrage im April 2020. Z Rheumatol 2020;79:584-9.

3 Dejaco C, Alunno A, Bijlsma JW, et al. Influence of COVID-19 pandemic on decisions for the management of people with inflammatory rheumatic and musculoskeletal diseases: a survey among EULAR countries. Ann Rheum Dis 2020. doi:10.1136/ annrheumdis-2020-218697. [Epub ahead of print: 06 Nov 2020].

4 Perniola S, Alivernini S, Varriano V, et al. Telemedicine will not keep us apart in COVID-19 pandemic. Ann Rheum Dis 2020. doi:10.1136/ annrheumdis-2020-218022. [Epub ahead of print: 05 Jun 2020].

5 López-Medina C, Escudero A, Collantes-Estevez E. COVID-19 pandemic: an opportunity to assess the utility of telemedicine in patients with rheumatic diseases. Ann Rheum Dis 2020. doi:10.1136/annrheumdis-2020-218008. [Epub ahead of print: 05 Jun 2020].

6 Solomon DH, Rudin RS. Digital health technologies: opportunities and challenges in rheumatology. Nat Rev Rheumatol 2020;16:525-35.

7 Győrffy Z, Radó N, Mesko B. Digitally engaged physicians about the digital health transition. PLoS One 2020;15:e0238658.

8 Knitza J, Simon D, Lambrecht A, et al. Mobile health usage, preferences, barriers, and eHealth literacy in rheumatology: patient survey study. JMIR Mhealth Uhealth 2020;8:e19661.

9 Richter JG, Chehab G, Kiltz U, et al. Digital health in Der Rheumatologie - Statuserhebung 2018/19. Dtsch Med Wochenschr 2019;144:e3.

10 Knitza J, Vossen D, Geffken I, et al. Nutzung von Medizin-Apps und Online-Plattformen unter deutschen Rheumatologen : Ergebnisse der rheumadocs-Recherche und DGRh-Kongress-Umfragen von 2016 und 2018. Z Rheumatol 2019;78:839-46.

11 Knitza J, Tascilar K, Messner E-M, et al. German mobile Apps in rheumatology: review and analysis using the mobile application rating scale (MARS). JMIR Mhealth Uhealth 2019;7:e14991.

12 Gerke S, Stern AD, Minssen T. Germany's digital health reforms in the COVID-19 era: lessons and opportunities for other countries. NPJ Digit Med 2020;3:94

13 Krusche M, Klemm P, Grahammer M, et al. Acceptance, usage, and barriers of electronic patient-reported outcomes among German rheumatologists: survey study. JMIR Mhealth Uhealth 2020;8:e18117.

14 van der Heijde D, Aletaha D, Carmona L, et al. 2014 update of the EULAR standardised operating procedures for EULAR-endorsed recommendations. Ann Rheum Dis 2015;74:8-13.

15 Najm A, Nikiphorou E, Kostine M, et al. EULAR points to consider for the development, evaluation and implementation of mobile health applications Aiding self-management in people living with rheumatic and musculoskeletal diseases. RMD Open 2019;5:e001014.
16 Powley L, Mcllroy G, Simons G, et al. Are online symptoms checkers useful for patients with inflammatory arthritis? BMC Musculoskelet Disord 2016;17:362.

17 Eysenbach G. Improving the quality of web surveys: the checklist for reporting results of Internet E-Surveys (cherries). J Med Internet Res 2004;6:e34.

18 Burmester GR. Rheumatology 4.0: big data, wearables and diagnosis by computer. Ann Rheum Dis 2018;77:963-5.

19 Proft F, Muche B, Spiller L, et al. Performance of the ankylosing spondylitis disease activity score based on a quick quantitative C-reactive protein assay in patients with axial spondyloarthritis. Joint Bone Spine 2020;87:69-73.

20 Gossec L, Guyard F, Leroy D, et al. Detection of flares by decrease in physical activity, collected using wearable activity Trackers in rheumatoid arthritis or axial spondyloarthritis: an application of machine learning analyses in rheumatology. Arthritis Care Res 2019;71:1336-43.

21 Kulcsar Z, Albert D, Ercolano E, et al. Telerheumatology: a technology appropriate for virtually all. Semin Arthritis Rheum 2016;46:380-5.

22 Ferucci ED, Day GM, Choromanski TL, et al. Outcomes and quality of care in rheumatoid arthritis with or without video telemedicine follow-up visits. Arthritis Care Res 2020.

23 Gordon HS, Solanki P, Bokhour BG, et al. "I'm Not Feeling Like I'm Part of the Conversation" Patients' Perspectives on Communicating in Clinical Video Telehealth Visits. J Gen Intern Med 2020;35:1751-8.

24 Menage J. Why telemedicine diminishes the doctor-patient relationship. BMJ 2020;371:m4348.

25 Zengin O, Onder ME. Youtube for information about side effects of biologic therapy: a social media analysis. Int $J$ Rheum Dis 2020;23:1645-50.

26 Hirsch MC, Ronicke S, Krusche M, et al. Rare diseases 2030: how augmented Al will support diagnosis and treatment of rare diseases in the future. Ann Rheum Dis 2020;79:annrheumdis-2020-217125-3.

27 Knitza J, Knevel R, Raza K, et al. Toward earlier diagnosis using combined eHealth tools in rheumatology: the joint pain assessment scoring tool (JPAST) project. JMIR Mhealth Uhealth 2020;8:e17507.

28 Kataria S, Ravindran V. Digital health: a new dimension in rheumatology patient care. Rheumatol Int 2018;38:1949-57.

29 Krusche M, Burmester GR, Knitza J. Digital crowdsourcing: unleashing its power in rheumatology. Ann Rheum Dis 2020;79:1139-40.

30 Knitza J, Callhoff J, Chehab G, et al. Positionspapier der Kommission Digitale Rheumatologie der Deutschen Gesellschaft für Rheumatologie e. V.: Aufgaben, Ziele und Perspektiven für eine moderne Rheumatologie. Z Rheumatol 2020;79:562-9.

31 Oltermann P, 2020. Available: https://www.theguardian.com/world/ 2020/sep/23/glitches-dent-german-enthusiasm-for-covid-contacttracing-app [Accessed 11 Nov 2020].

32 Wilcock AD, Rose S, Busch AB, et al. Association between broadband Internet availability and telemedicine use. JAMA Intern Med 2019. doi:10.1001/jamainternmed.2019.2234. [Epub ahead of print: 29 Jul 2019]. 